
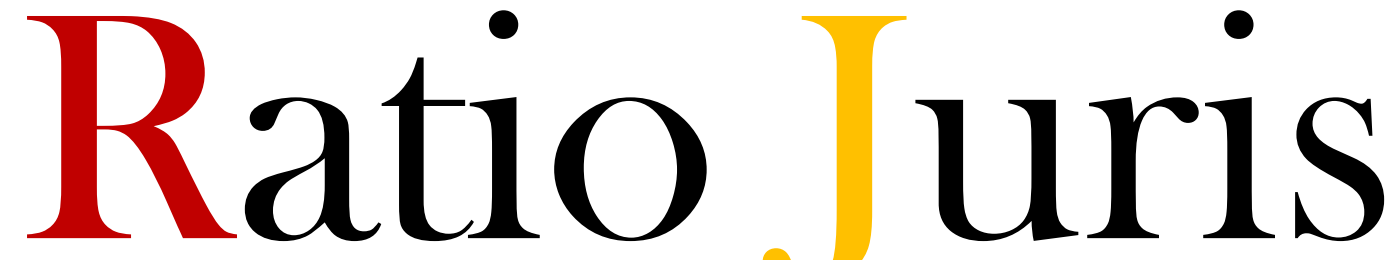

Publicación Semestral de la Facultad de Derecho UNIVERSIDAD AUTÓNOMA LATINOAMERICANA

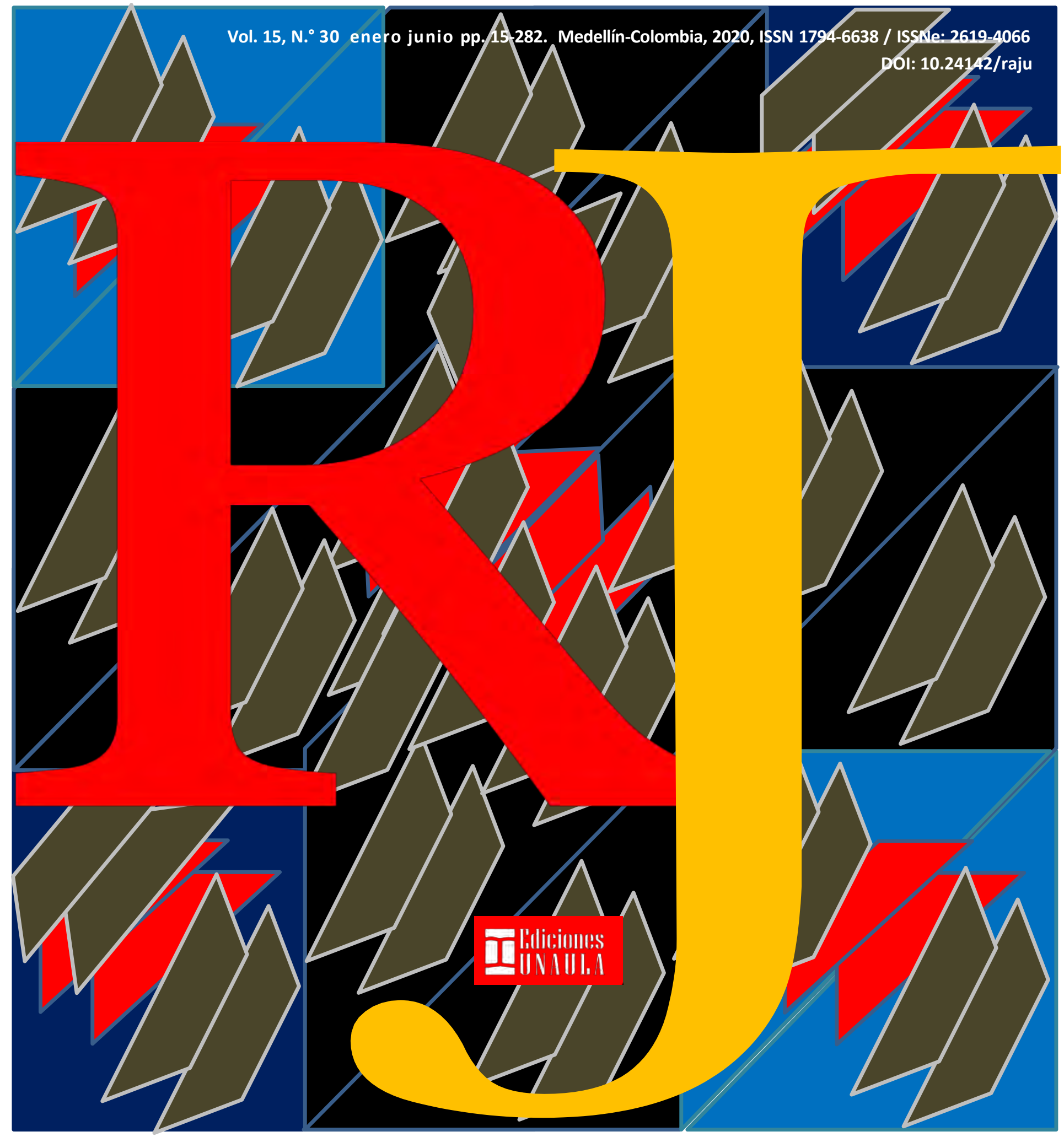




\title{
Significaciones imaginarias y ciudadanía políticos en jóvenes protestantes evangélicos en Iberoamérica ${ }^{1}$
}

\author{
Imaginary meanings and political citizenship in young evangelical \\ Protestants in Latin America
}
Significados imaginários e cidadania política em jovens protestantes evangélicos na América Latina

\author{
Rafael Ángel Gómez-Gallego² \\ Claudia María Muñoz-García ${ }^{3}$
}

Recibido: 20 de junio de 2019 - Aceptado: 20 de abril de 2020 - Publicado: 30 de junio de 2020 DOI: $10.24142 /$ raju.v15n30a5

\begin{abstract}
Resumen
El presente artículo, aborda el estado del arte en torno al conocimiento producido en la relación de las categorías de significaciones imaginarias y ciudadanía política, durante el periodo 2007-2018 en Iberoamérica. Este estado del arte, se realiza con el objetivo de identificar las tendencias teóricas, metodológicas y los resultados más relevantes, que han orientado las investigaciones respecto a dichas categorías, en su relación analítica, con el fin de fundamentar posteriores análisis que permitan identificar y problematizar los avances y vacíos en el campo, que ayuden a ampliar la mirada sobre estos asuntos, en el marco de la investigación doctoral "Significaciones imaginarias en torno a la ciudadanía y la religiosidad, en un grupo

\footnotetext{
${ }^{1}$ Este artículo de investigación es una revisión derivada del desarrollo de la investigación doctoral denominada "Significaciones imaginarias en torno a la ciudadanía política instituida e instituyente, en jóvenes protestantes evangélicos de Colombia" En la universidad de Manizales en convenio con CINDE.

${ }^{2}$ Adelanta estudios de doctorado en Ciencias sociales niñez y juventud en la universidad de CINDE- Manizales Orcid: $\quad$ https://orcid.org/0000-0003-2361-6468 Google Scholar: https://scholar.google.com/citations?user=dEmAcucAAAAJ\&hl=es Email: Rangel.gomez@hotmail.com ${ }^{3}$ Docente investigadora, profesora titular Universidad Libre- Pereira (Colombia); Tutora de tesis del Doctorado en Ciencias Sociales, Niñez y Juventud del convenio CINDE- Universidad de Manizales Orcid: https://orcid.org/0000-0001-9247-7866 Google Scholar: https://scholar.google.es/citations?user=IVyOrxYAAAAJ\&hl=es Email claudiamgm17@hotmail.com
} 
de jóvenes universitarios de Pereira", la cual se encuentra en proceso de construcción y ejecución

Palabras claves: Significaciones Imaginarias; ciudadanía política; juventud y religión

\begin{abstract}
:
This article addresses the state of the art around the knowledge produced in the relation of the categories of imaginary meanings and political citizenship, during the period 2007-2018 in Ibero-America. This state of the art is carried out with the purpose of identifying the theoretical, methodological trends and the most relevant results, which have guided the investigations regarding these categories, in their analytical relationship, in order to support subsequent analysis that allows identify and problematize the advances and gaps in the field, which help to broaden the perspective on these issues, within the framework of the doctoral research "Imaginary meanings around citizenship and religious beliefs, in a group of young university students from Pereira", which is in the process of construction and execution.
\end{abstract}

Keywords: Imaginary Meanings, political citizenship, youth, and religion

\title{
Resumo
}

Este artigo aborda o estado da arte em torno do conhecimento produzido na relação das categorias de significados imaginários e cidadania política, durante o período 2007-2018 na Ibero-América. Esse estado da arte é realizado com o objetivo de identificar as tendências teóricas, metodológicas e os resultados mais relevantes, que orientaram as investigações sobre essas categorias, em sua relação analítica, a fim de subsidiar análises subsequentes que permitam identificar e problematizar os avanços e lacunas no campo, que ajudam a ampliar a perspectiva sobre essas questões, no âmbito da pesquisa de doutorado "Significados imaginários sobre cidadania e religiosidade, em um grupo de jovens universitários de Pereira", que está em processo de construção e execução

Palavras-Chave: Significados Imaginários; cidadania política; juventude e religião

\section{Introducción}

El presente estado del arte desarrolla la fundamentación del campo temático y problemático de la investigación doctoral en desarrollo titulada "Significaciones imaginarias en torno a la ciudadanía y la religiosidad, en un grupo de jóvenes universitarios de Pereira", la cual plantea como interés central de indagación, el proceso de configuración de las significaciones imaginarias, en un grupo de jóvenes universitarios pertenecientes a diversos cultos religiosos en Colombia, en torno a la ciudadanía política instituida e instituyente. De esta problematización, se 
derivan las siguientes preguntas: ¿Qué significaciones imaginarias están presentes, en jóvenes pertenecientes a diversos cultos religiosos, en torno a la ciudadanía política instituida? ; ¿Qué significaciones imaginarias dan cuenta de los desplazamientos, las resistencias y las emergencias en torno a una ciudadanía política instituyente, en jóvenes de diversos cultos religiosos?, ¿Cómo dialogan y se imbrican las significaciones imaginarias de ciudadanía política instituida e instituyente en un grupo de jóvenes pertenecientes a diversos cultos religiosos en Colombia?; ¿Qué prácticas con relación al ejercicio de la ciudadanía política instituida e instituyente, se manifiestan en un grupo de jóvenes pertenecientes a diversos cultos religiosos en Colombia?. A partir de este contexto problémico, surge el interés específico por conocer inicialmente, el estado del conocimiento producido sobre las significaciones imaginarias en relación con la ciudadanía política en jóvenes que profesan como opción religiosa el protestantismo evangélico.

Estas preguntas orientan una reflexión crítica sobre dicho conocimiento, a partir de la revisión amplia, aunque en ningún momento exhaustiva, acerca de las investigaciones realizadas en este campo, que invitan a tener una mirada amplia sobre dicho conocimiento producido en los últimos doce años, en el contexto Iberoamericano. Las categorías analíticas abordan las significaciones imaginarias, en su relación con la ciudadanía política, expresada en aquellos jóvenes que profesan como opción religiosa el protestantismo evangélico, con el fin de identificar las tendencias que han orientado la indagación de este campo, sus objetivos, los sujetos de investigación que la convocan, las teorías, las metodologías y los resultados generados, con el fin de aportar de una manera general, al campo de las ciencias sociales.

Así, con el fin de alcanzar el objetivo propuesto, este estado del arte se desarrolló en dos fases. La primera fue el rastreo y selección de antecedentes; en este paso, se buscaron tesis postdoctorales, doctorales y artículos de investigación de autores independientes, en las bases de datos académicas, utilizando como criterio de búsqueda, marcadores semánticos asociados a las categorías analíticas referenciadas, tales como significaciones imaginarias, ciudadanía, democracia, construcción de paz, educación para la democracia, ética y liderazgo. Posteriormente se seleccionaron aquellos documentos ubicados en el periodo seleccionado, que contenían al menos dos de los marcadores semánticos descritos, a partir de lo cual se configuró un cuerpo analítico integrado por cincuenta trabajos que coinciden con los criterios geográficos, temporales y temáticos para el relevamiento bibliográfico.

La segunda fase consistió en la organización y análisis de dichos antecedentes. Para esto, se sistematizó la información en matrices descriptivas a partir del contenido textual de las fuentes consultadas, identificando en una primera lectura, los 
fragmentos de texto cuyos contenidos relevantes, permitan dar cuenta de las premisas teóricas, los abordajes metodológicos y los resultados relevantes, a partir de lo cual se identifican las relaciones entre dichos contenidos textuales, para luego construir campos categoriales emergentes que nos permitiesen una meta-lectura de lo encontrado.

\section{Resultados}

En el siguiente aparte, presentaré los resultados obtenidos dentro del presente estado del arte, de acuerdo con los tres niveles aplicados para el análisis de contenido: nivel descriptivo. Nivel analítico y nivel hermenéutico propiamente, en el cual se sintetizarán los hallazgos más significativos.

\section{Nivel descriptivo}

El rastreo realizado muestra una alta producción de conocimiento en estos temas, en América Latina. Como se puede observar en el gráfico de barras, el estado del arte se concentra en los países de Colombia, España, Chile, Argentina, México y Ecuador. De los 50 trabajos revisados, el $82 \%$ corresponden a países latinoamericanos y el 18, \% a España. En general se encontró, en este primer nivel de análisis descriptivo que, el $50 \%$ de los trabajos producidos se ubican en Colombia, seguidos de España con $18 \%$, Chile con $12 \%$, Argentina 10\%, México $8 \%$, Ecuador $2 \%$

Figura 1. Distribución de la producción bibliográfica, según la región

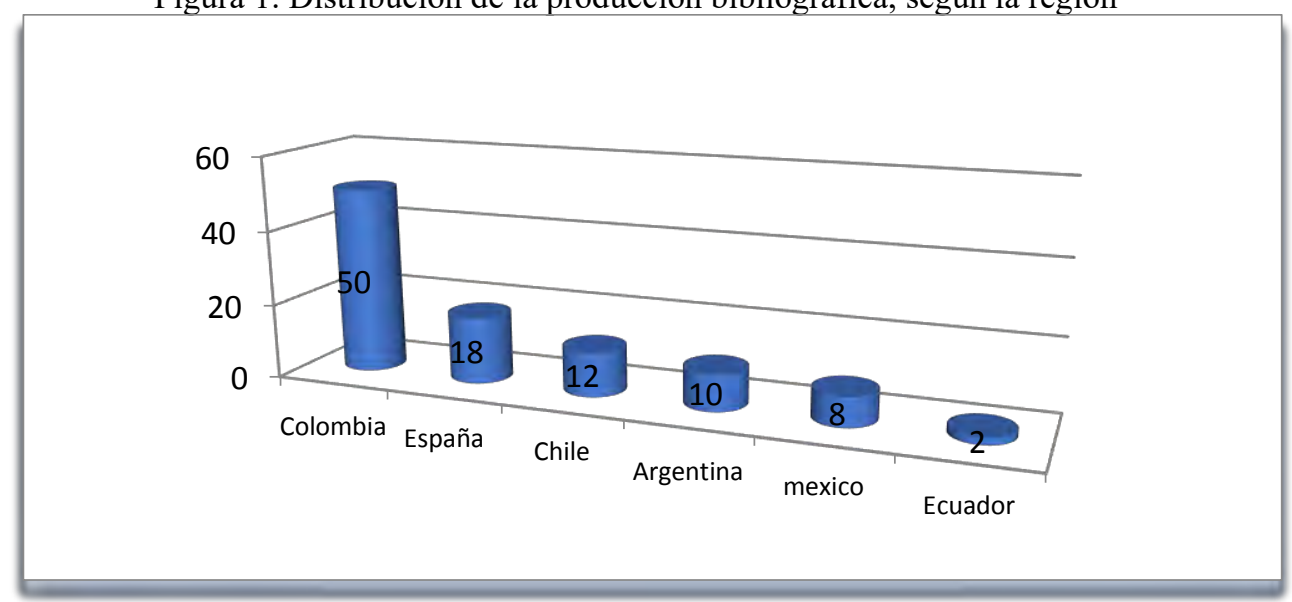

Fuente: Elaboración propia.

En relación con el tipo de documento revisado, se encontró la siguiente clasificación: trabajos posdoctorales el $8 \%$, tesis doctorales $8 \%$; proyectos de grado 
de maestría, el $12 \%$, y $72 \%$ capítulos de libros, investigaciones individuales e investigaciones colectivas.

Figura 2. Distribución de la producción bibliográfica, según tipo de documento

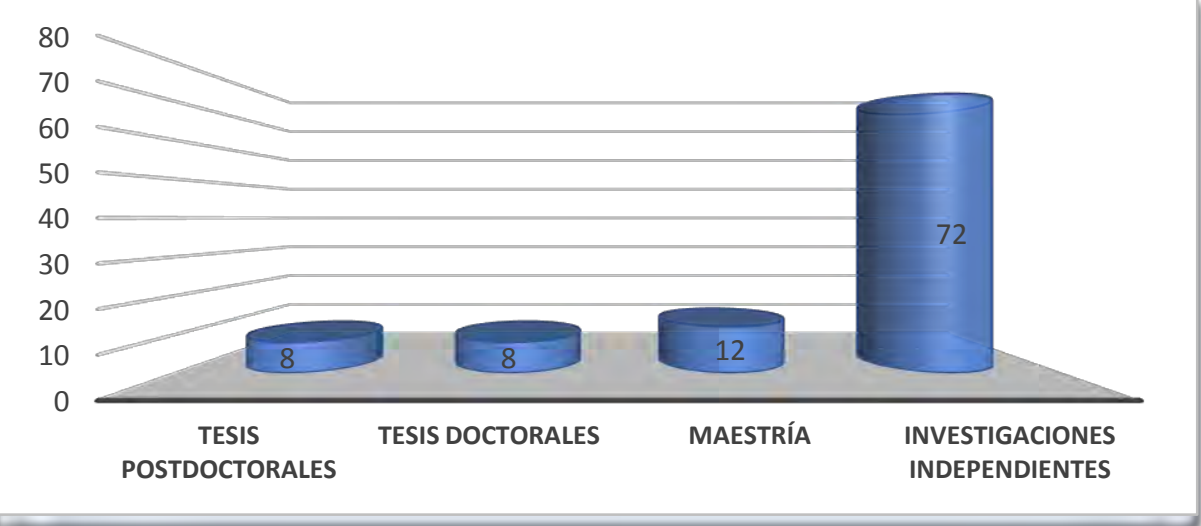

Fuente: Elaboración propia

Del total de los trabajos revisados, el 54\% corresponde al campo de las ciencias sociales, mientras que el $46 \%$ se refiere a investigaciones disciplinares, especialmente desde las miradas teológica, educativa, psicológica y de la religión.

Figura 3. Distribución de la producción bibliográfica, según las disciplinas

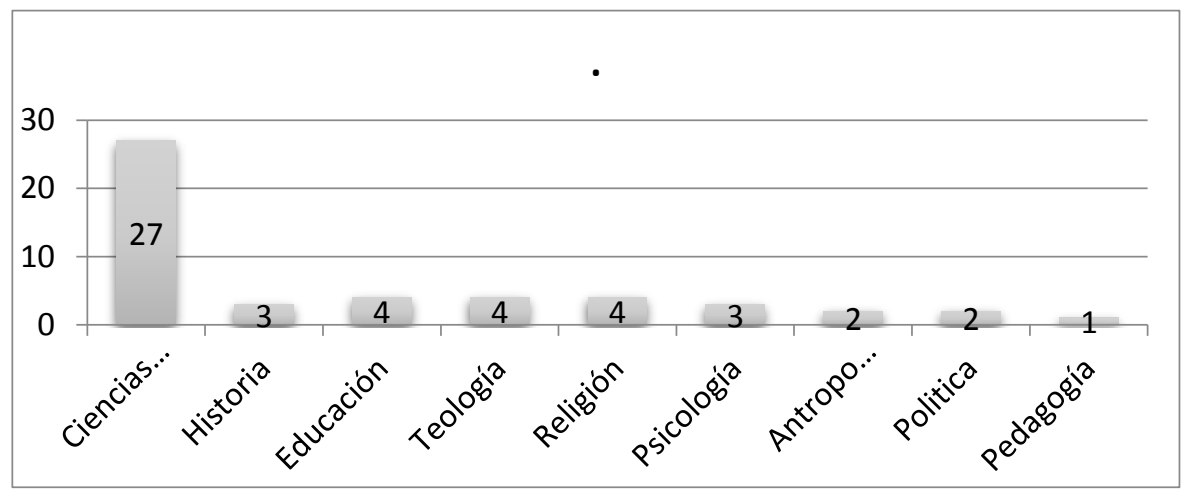

Fuente: Elaboración propia del autor.

Respecto a los enfoques metodológicos predominantes, se evidenció que el $98 \%$ responde a una perspectiva cualitativa. De ellos, el $45 \%$ responde a trabajos que hicieron contacto directo con fuentes vivas, el 55\% corresponde a trabajos de revisión documental y artículos de reflexión de tipo teórico. En consecuencia, la 
información recogida permitió derivar análisis y encontrar tendencias sobre el comportamiento, las prácticas discursivas y los sentidos predominantes significados en los sujetos de estudio.

En cuanto a los métodos empleados, se evidenciaron tres tendencias de acuerdo a la prevalencia que mostraron: La primera y menos representativa fue el empleo del método mixto con un $4 \%$, la segunda, el uso del método crítico con un $26 \%$, y la tercera, la aplicación del método hermenéutico de corte fenomenológico con un $70 \%$. Puede entonces concluirse, que la mayoría de las investigaciones emplearon un método comprensivo, buscando dar cuenta del sentido esencial de los fenómenos, así como se interrogaron por la importancia que éste tiene en relación con los objetos estudiados.

En lo que tiene que ver con las técnicas empleadas para obtener la información, se destaca el uso de entrevistas a profundidad como la forma más usada para interactuar con los sujetos de la investigación. También se usaron cuestionarios de tipo descriptivo, así como grupos focales, talleres lúdicos y observación. En cuanto los estudios documentales, se observó una predominancia en el uso de instrumentos como fichas bibliográficas, fichas hemerográficas, fichero, Registro de páginas electrónicas, etc...

Figura 4. Distribución de la producción bibliográfica, según el método.

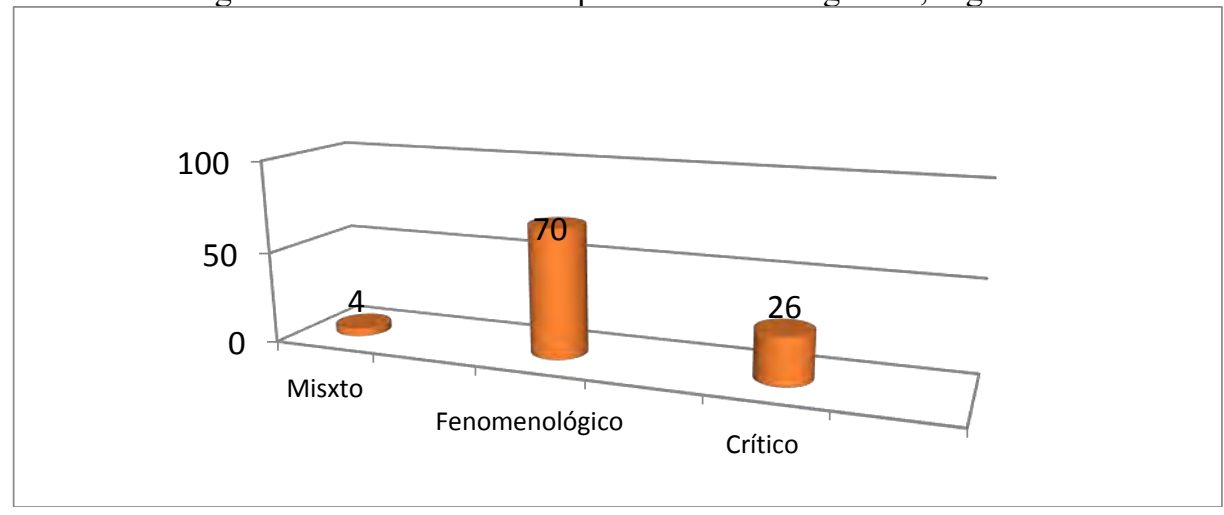

Fuente: Elaboración propia

En cuanto a las técnicas de análisis utilizadas, se identificó que, en las investigaciones estudiadas, se usaron diferentes tipos así: el narrativo con un $28 \%$, el análisis de discurso con un $11 \%$, y el análisis de contenido con un $65 \%$. Las técnicas de corte empírico se orientan a la recolección de material experiencial a través de los relatos y las narrativas. En todos estos trabajos, el interés desarrollado por el investigador es claramente descriptivo. 
Figura 5. Distribución de la producción bibliográfica, según el tipo de técnica de análisis

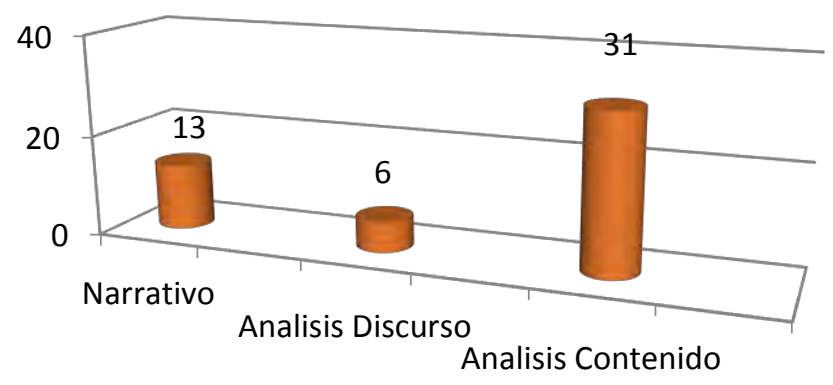

Fuente: Elaboración propia.

Finalmente, a partir de las nociones principales de estas investigaciones, se retomaron las categorías de análisis y categorías empíricas definidas previamente para la selección del corpus documental, encontrando la siguiente distribución:

Figura 6. Distribución de la producción bibliográfica, según las categorías.

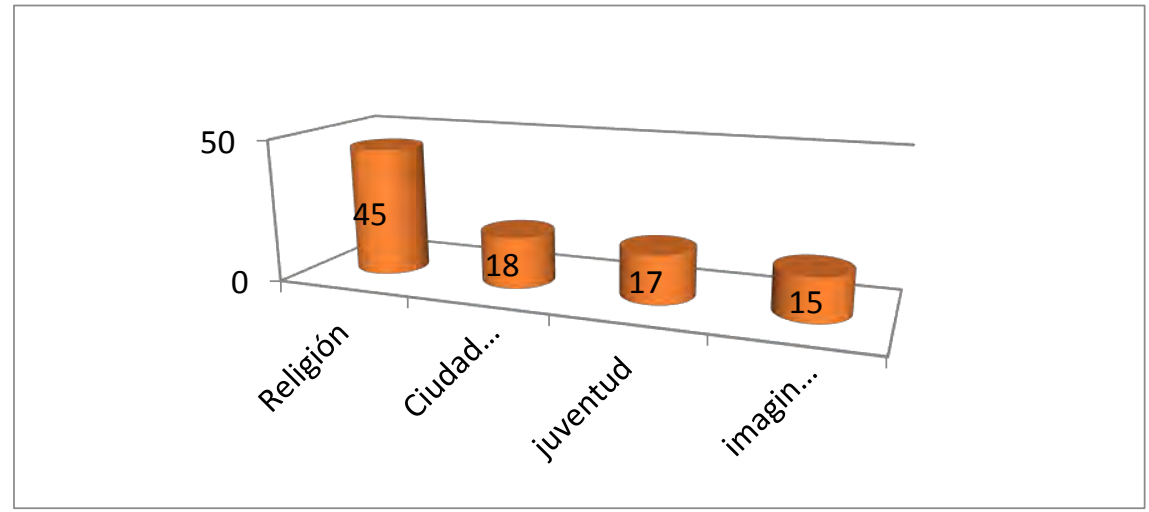

Fuente: Elaboración propia.

\section{Análisis de los resultados}

\section{Sobre la categoría imaginarios.}

En el análisis de la categoría "Imaginarios", se observó un interés predominante por abordarla en su relación con categorías diversas y bajo relaciones teóricas que han derivado hacia otras temáticas, las cuales se consideran más interesantes o productivos. Seguramente han quedado en la opacidad muchas referencias 
interesantes, pero el sentido que tienen estas investigaciones es servir de provocación, de introducción a una vía que hasta ahora no ha sido suficientemente transitada, buscando animar a otros investigadores a ampliar y profundizar las referencias aquí iniciadas.

En forma más precisa, en cuanto a los resultados de las investigaciones cuyo núcleo de interés son los imaginarios sociales, podemos resaltar a Espinosa ( 2007) el cual analiza las formas exteriores a las culturas locales y la manera como se sitúan en la memoria y hallan vida en los sueños y fantasías, y se insertan y afectan en sentido bidireccional en la realidad y el imaginario colectivo; de forma que el campo de la ficción, de la narración liberada de toda ceremonia, pasa fortuitamente por el sueño y va del mito a la "creación-ficción". Es en este contexto teórico que Aliaga y Pintos. (2012) resaltan el interés investigativo por los imaginarios sociales, como categoría analítica para el conocimiento de realidades sociales locales la cual, en las dos últimas décadas, ha alcanzado notables aportes al conocimiento desde distintos países, especialmente el hispanoamericano.

En otros estudios hallamos en Velázquez (2013) un abordaje sobre el imaginario considerado como noción central en el análisis de la sociedad y su relación con su entorno tanto en lo histórico como en lo geográfico; en ese sentido, el autor estudia los imaginarios construidos en la ciudad-metrópoli. Entender los imaginarios sobre la metrópoli, es aprehender las estructuras que instituyen los procesos, permitiendo organizar una comunidad y por tanto a una ciudad, en tanto territorio o región, puesto que el imaginario aporta la matriz de sentido derivadas de las representaciones sociales que en la ciudad circulan y que la transforman simbólicamente, convirtiéndose tanto en trazadores para el análisis como guías para la acción.

Por su parte, Cifuentes (2015) investiga sobre los imaginarios construidos alrededor del conflicto, al interior de las instituciones educativas, concluyendo que estos están determinados en gran parte por los roles que ocupa cada estamento de la comunidad educativa, dentro de la institución escolar; así mismo, señala el evidente cambio de paradigma religioso que se está produciendo en las sociedades iberoamericanas.

También se observan los aportes de De Ävila (2015), quien devela las configuraciones socio-imaginaria claramente diferenciado y hegemónico, en torno a lo juvenil, en la sociedad chilena contemporánea; dichos imaginarios están referidos al reto de escolarización continua. Se plantea entonces a manera de hipótesis para próximas investigaciones, la urgencia de un imaginario social entorno a lo juvenil como una construcción de politización que surge de las presentes tensiones de diversos actores sociales, dirigidas a impulsar profundas innovaciones socio-estructurales en la sociedad chilena. 
De otra parte, el estudio de Álvarez y Álvarez (2016), muestra el proceso de como las representaciones sociales se forman y transforman, alrededor de las experiencias y trayectoria de vida. En este caso particular, se muestran las representaciones sociales que se generan alrededor de la vida de los jóvenes, tales como las prácticas religiosas en las tradiciones familiares, el grupo social en el que se desenvuelven y la formación escolar entre otros; estas representaciones contribuyen a afianzar o derribar el sistema de creencias y actitudes propias que se van forjando en torno a la religión, develando las prácticas de consumo que hay alrededor de la religión católica.

De acuerdo con, Torres (2016), se pregunta por los imaginarios, en su relación con la sociedad y la comunicación, plateando que la sociedad contemporánea es compleja y su realidad es pluricontextual; de igual forma, asume que los imaginarios sociales son cambio constante y a su vez, revolución.

En este mismo propósito de analizar la categoría de Imaginarios observamos en Gómez (2017) la integración analítica de tres planos de significación para los imaginarios: (i) una perspectiva de los esquemas fundamentales de las representaciones; (ii) un espacio donde se extiende la acción simbólica por el desarrollo de la función semiótica y (iii) el área de las ordenes normativa de significación. Desde este último plano, se presenta la orden de los sistemas de representación que administran la producción discursiva.

Lo imaginario y la memoria colectiva (IMC) constituyen una totalidad simbólica por referencia a la cual se define un grupo en virtud de la cual ese grupo se reproduce en el universo imaginario generación tras generación. El complejo IMC ciertamente de forma a los mundos imaginarios y a las memorias individuales (Auge, 1999). Así se halla en Hurtado (2017) una investigación que se transforma en punto de partida para el estudio de las significaciones imaginarias, a nivel conceptual y metodológico. En lo conceptual porque conlleva a nutrir desde la experiencia empírica los referentes que fueron planteados por Cornelius Castoriadis (2007) y Norbert Elías (2008) en cuanto a las significaciones imaginarias y su configuración. En lo metodológico, evidencia la necesidad de transformar unos diseños alternativos que restrinjan los imaginarios instituidos y puntualicen y visibilicen la capacidad innovadora del ser humano. Esto determinada dejar atrás la idea de que existe una univocidad, un imaginario social, una sociedad, un solo sentido, una única verdad, y un solo método, para asumir desde esa perspectiva los conceptos en plural; dando espacio a las mixturas, las hibridaciones y a los lugares liminales que no caben las miradas esenciales y deterministas. 
Ahora bien, tanto Castoriadis (2007) como Molina y Álvarez (2017) aportan al conocimiento sobre los imaginarios en torno a la juventud, resaltando como las épocas nutren de diverso material los procesos y elementos simbólicos que trabajan como un "magma de significaciones" en la institución imaginaria social de los jóvenes, el cual es base de la configuración social en una época histórica determinada.

Por último, en este análisis sobre esta categoría de los imaginarios, se descubre en Gaona (2018), el abordaje de las representaciones sociales, en su relación con los movimientos protestantes en Colombia, durante la primera mitad del siglo XX. En dicha investigación, se muestran las reivindicaciones sociales de estos movimientos religiosos, en términos contextuales, discursivos y prácticos, además de tratar el tema del ingreso de la mujer a la vida pública.

Ahora bien, en algunas de estas investigaciones se proponen horizontes de conocimiento, orientados a identificar la forma en que los jóvenes evangélicos se representaron a sí mismos en Colombia durante la primera mitad del siglo XX; estos aspectos son enfocados desde la Semiótica del discurso en cuanto proceso social, señalando la necesidad de realizar abordajes de la categoría de imaginarios sociales, presentes en jóvenes del movimiento estudiantil, en relación con los procesos de producción de sentido y construcción social de la realidad a través de prácticas comunicativas, con particular referencia a la comunicación mediática, con especial atención al mundo audiovisual como recurso clarificador. De esta forma, los imaginarios sociales sobre lo urbano están presentes en manifestaciones como la capoeira, el death metal, el teatro y el skate bording los cuales son considerados zonas de libertad transitoria y espacios de posibilidad para configurar nuevos imaginarios.

Del anterior panorama de trabajos, surgen tres tendencias en torno a la definición de imaginarios sociales; la primera, asume el imaginario como algo "inventado" ya se trate de un "invento absoluto" o de un deslizamiento o desplazamiento de sentido, en el que unos símbolos ya disponibles están investidos con otras significaciones diferentes a las consideradas "normales o canónicas"; los imaginarios son creación radical, que mediante complejos procesos de aceptación y legitimación adquieren el carácter de social, en tanto elementos fundacionales. La segunda tendencia, sostiene que los imaginarios son construcciones colectivas y anónimas que mantienen unidad a la sociedad. El vínculo de la vida social que mantiene unidas las ideas, las representaciones, los actos; son simplificaciones de la complejidad inabarcable de la comunicación; por lo tanto, son simplificaciones de la sociedad, con la peculiaridad que es la propia sociedad quien los construye. Unos paradigmas de las significaciones imaginarias sociales pueden ser: los mitos, los espíritus, los dioses, los tabúes, los tótems, la familia, la justicia, la soberanía, el ciudadano, el capital, la mercancía, el Estado entre otras. La tercera tendencia 
sostiene que el imaginario social, por su parte, es una expresión que otros autores e investigadores sociales han asociado con palabras como: conciencia colectiva, ideología, mentalidad social, aún algunos lo relacionan con el concepto de representación social; sin embargo, la capacidad del sujeto humano de crear significaciones está referida fundamentalmente a su imaginación radical. En síntesis, se evidencia que los imaginarios sociales son abordados por disciplinas científicas, en las cuales se plantean diferentes relaciones orientadas a comprender esta categoría como instrumento para la representación y método de organización del conocimiento.

Analizadas las investigaciones seleccionadas para encontrar caminos que permitan comprender mejor la categoría de los imaginarios, avancemos a la segunda categoría.

\section{Sobre la categoría de juventud.}

Los siguientes estudios analizados, contribuyen a la mejor comprensión de la categoría Juventud. Así Leyton (2009) plantea tres aproximaciones para desarrollar el análisis crítico sobre las definiciones de lo juvenil: juventud como categoría etérea, la juventud como etapa de la vida, y la juventud como subcultura. De otra parte, interpretando a Oziel (2007) afirma que la juventud debe considerarse como una etapa transitoria de la vida. El joven es receptivo, es abierto a las trasformaciones que se presentan en las comunidades. Ellos están en una búsqueda de identidad, se abren aminos para proyectarse por medio de imágenes que hablen de sí mismo, de su forma de actuar, de pensar, de sentirse de dar sentido a su entorno por medio de su lenguaje corporal, de su forma de vestir. También, Benedct (2008), comprende la juventud como procesos de transición desde la cuna hasta la edad avanzada.

Sin embargo, Montaño y Villota (2016) citando a Alvarado y Patiño (2013), en relación con el sujeto joven político, sostienen al igual que Bolívar (2000) que la juventud es una etapa en sí misma de manera que no es ninguna transición a la madurez, ni una franja de la vida que esperamos para tomar decisiones. La etapa de la juventud, como la describen los autores mencionados, es una fase de la vida de todo ser humano, donde hay unas pérdidas y unas ganancias, cuyos resultados se pueden ver en el futuro.

Desde la postura de Kringer (2014), compartida y ampliada por Mosquera (2011) y Urresti (2000), se enfatiza en la necesidad de comprender a los jóvenes en el momento histórico y social en el que están insertos. Es superado por lo tanto todo esencialismo como lo describe Bourdieu (1990), La juventud debe ser estudiando como construcción histórica y social, no solamente como un dato biológico, pues el propósito es configurar diferentes formas de ser joven, en cada momento 
histórico y encada posicionamiento de un mismo espacio tiempo social, lo que hace imposible ser homogenizados bajo un mismo concepto cultural.

Siguiendo los aportes de Molina y Álvarez (2015), la juventud es entendida como construcción socio-imaginaria y simbólica que se extiende a partir de estructuras sociales concretas e históricas situadas. En igual sentido, Hurtado (2017), la considera como un imaginario social, alrededor del cual se generan significaciones de lo instituido y lo instituyente. Igualmente, este autor resalta que este imaginario social debe ser comprendido desde un análisis histórico-cultural pero también empírico. Tomando la noción de Imaginario radical de Castoriadis (1997), Hurtado sostiene que dicho imaginario se da en aquellos jóvenes capaces de modificarse mediante su fusión con el tejido social del cual hacen parte y a través de un compromiso contingente con su lugar; se trata pues, de jóvenes que crean significaciones imaginarias sociales a de los imaginarios sociales instituidos, convirtiéndose en constructores de nuevas metáforas que complejizan la comprensión del mundo.

Igualmente, a partir de la revisión bibliográfica se encontró que la concepción acerca de la categoría "Juventud", muestra al menos tres tendencias; la primera, hace referencia a la Juventud considerada como un período transitorio en la vida, Para Oziel (2007) y Leyton (2009), el joven tiene capacidad reformativa, es decir, genera trasformaciones y se resignifica a sí mismo. La segunda tendencia, considera que la juventud debe ser analizada como una construcción histórica y social. Tanto Kringer, Mosquera, Urresti, y Bourdieu, ya mencionados, resaltan la trascendencia de la juventud, siempre determinada por el contexto sociohistórico. La tercera tendencia, planteada por Molina y Álvarez Hurtado, ambos sustentados en Castoriadis, nos permiten comprender la categoría Juventud, como un imaginario social alrededor del cual se presenta imaginarios que se movilizan entre lo instituido y lo instituyente.

En cuanto a las preguntas y apuestas investigativas en torno a la categoría "Juventud", se reconoce en primer lugar, un interés prevalente por los factores que influyen en la percepción del joven hacia la política; en segundo lugar, se abordan los fundamentos políticos, jurídicos y educativos para la participación juvenil, en lo público y en lo político; en tercer lugar, se aborda el asunto de la inclusión de diversos actores, en lo concerniente a las diversas prácticas ciudadanas y las formas de participación en sus expresiones juveniles y por último, se estudia la relación de los jóvenes y la religión.

Este análisis sobre la categoría de la juventud permite comprender los diferentes acercamientos que se han construido con el fin de tener un sentido más claro sobre este concepto. Es así como obtenemos las referencias que van desde una juventud comprendida como etérea, etapa de la vida, subcultura, periodo transitorio de la 
vida, subcultura, una etapa en sí misma o una fase de la vida. La juventud, también es vista como etapa de apertura y receptividad a los grandes cambios que le exigen su contexto político, social o religioso. Los jóvenes van en búsqueda permanente de su identidad, se proyectan a través de una imagen de sí mismos, de su modo de sentir, pensar y de darle sentido a su realidad.

Se resalta entonces la importancia de comprender a los jóvenes en el espaciotiempo, en el momento y la construcción histórica y cultural en la que están insertos. Comprenderlos a partir de los procesos socio-imaginarios y simbólicos que los constituye y que los sitúa en estructuras sociales concretas.

Se llega, por lo tanto, a una relación que permite dar más luz a este trabajo de investigación y es la comprensión de la juventud como imaginario social en torno al cual se construyen significaciones de lo que ha llamado Castoriadis (1997) lo instituido y lo instituyente. La juventud se configura como un imaginario seductor, a través de ideaciones performativas que son valoradas en una sociedad, apoyadas por metáforas de la existencia perenne en el mundo.

Analizadas las investigaciones seleccionadas para encontrar caminos que permitieran comprender mejor la categoría de la juventud, avancemos a la tercera categoría.

\section{Sobre la Categoría de Religión}

Una categoría tan polisémica como lo es la Religión se amplía hacia muchas dimensiones que no es posible abordar en este artículo. En aras de precisar el marco conceptual del tema abordado, se enfatiza sobre la relación entre condición juvenil y religión, específicamente en el contexto de movimientos religiosos que se insertan en un contexto social, donde buscan legitimar sus creencias; tal es el caso de la teología de la liberación, cuya doctrina tiene un fuerte énfasis e interés en los pobres y además sostiene que una de sus tareas, es demostrar la relevancia del texto sagrado como mediación sociológica, política, cultural y ecológica (Boff, 2009)

En esta misma línea de pensamiento, Fica (2010) en sus investigaciones sobre liberalismo y ascetismo protestante en la construcción de la ciudadanía en la Argentina de principios del Siglo XX, sostiene que la formación moral motivada por el protestantismo liberal fomentaba alianzas que interpelaban y disputaban la hegemonía con un imaginario de ciudadanía que se consolidaba hacías un década de los treinta, los cuales eran impulsados por el liberalismo nacional, corporativo, de raíces hispanizantes, vinculados al integralismo de la iglesia católica apostólica romana.

Otra investigación como la de Rebolledo (2013) hace también una relación entre el protestantismo y el liberalismo al sostener la posibilidad de advertir la relación 
política que entablaron los protestantes liberales con sectores oligarcas vinculados al cientificismo.

Analizar la categoría religión en Iberoamérica, es entrarnos a dos movimientos que han prevalecido por siglos como lo son el protestantismo y el catolicismo. Así, uno de los trabajos que sintetizan investigaciones sobre el cristianismo en América Latina, lo realiza Panotto (2015:) el cual plantea que los estudios se pueden agrupar en:

A. Concentrados en la participación de individuos creyentes en espacios institucionales, tales como partidos políticos o de la estructura burocrática estatal (Mallimci, 1996; Bianchi,1966, 199; Carbonelli, 2009; Wynarczyk,2010).

B. Trabajos vinculados a los discursos en el interior de comunidades religiosas (sean explicativos o implícitos), especialmente en espacio populares, sobre temáticas socia políticas reinterpretando a partir de coordenadas religiosas y teológicas (Samán, 2000 Algranti,2010; Miguez 2012)

C. Finalmente, aquellos estudios que analizan la participación ( o falta de ella ) en diversos campos sociales por parte de ciertas comunidades religiosas, con relación a ls discusiones en torno a los fenómenos dela laicidad y la ( post) secularización ( Mena, 2011; Montero, 2013; Cipriani, 2013). (p.65)

Aparte de los trabajos mencionados, también se analizaron algunas tesis, como por ejemplo la realizada por Gómez y Cogollo (2015) titulada "Asociación entre religiosidad y estilo de vida en adolescentes", en la cual concluye que la religiosidad de la población puede ser un punto para el diseño de intervenciones diferenciadas, orientadas a la promoción de comportamientos que favorezcan la salud y el bienestar general. Para este autor, la religión y la religiosidad se definen como: "Un conjunto de prácticas y experiencias colectivas alrededor de un sistema de creencias relacionadas con seres de naturaleza divina. Y la religiosidad, como el grado de compromiso, adherencia o participación en la creación t prácticas de una religión particular" (p.28).

Otra investigación desarrollada por Espinosa (2017) titulada "Los nuevos imaginarios religiosos de los jóvenes", resalta como aporte que algunas investigaciones en México han registrado la presencia creciente de imaginarios religiosos que provienen de una cultura globalizada. Así mismo, Martínez y Pineda (2016) señalan que la religión no es estática sino dinámica, tan dinámica que tiene el poder de transformarse en otros movimientos. 
En este contexto, se evidencia una fuerza del protestantismo, a partir de lo cual se desarrollan también movimientos como la teología de liberación, fundados por protestantes y teólogos católicos. Para Nájera (2007), se amplían los nuevos significados de "Dios" y la presencia de los imaginarios religiosos muestran que los individuos se alejan de su tradicional comportamiento ritual al encontrar otras formas más sencillas para su espiritualidad. Al respecto, Douglas (1988) manifiesta: "Nos encontrarnos, pues, con una reproducción fascinante, a pequeña escala, de la reforma protestante, fenómeno que vale la pena investigar con mayor determinación "(33). El autor, no se empeña en demostrar que el individuo carece de ritualidad, sino que, más bien, encontrar vías más simples y con menos carga de culpabilidad social y religiosa.

De otra parte, observamos en Gómez y Cogollo (2015), no solo la utilidad de la religión sino también la intensión de definirla como prácticas y experiencias colectivas en torno a seres de naturaleza divina, pero a partir de sus resultados investigativos, resaltan el papel de la religión para fortalecer las prácticas de salud y bienestar en general. Así mismo, Cifuentes, (2018), aborda la categoría "religiosidad" concluyendo que la sociedad actual ha pasado de ser una sociedad de cristiandad que incluía por tradición a todos en una misma cosmovisión religiosa, a una realidad religiosa plural y de elección estrictamente personal, sin que sea algo necesario. A ello ha contribuido la posmodernidad, caracterizada por afianzar el individualismo, en contra de la tradicional tendencia a asumir un tipo de religión normalmente comunitaria y de grandes masas, lo cual ha favorecido que las personas se orienten más por una búsqueda más íntima y sincrética. En dicho estudio también se analiza la religiosidad oriental, concluyendo que se trata de una expresión más espiritual y ligada a vivencias personales.

En cuanto a la pregunta y apuesta investigativa en torno a la categoría "religión", se evidencia un entramado que permite no solo profundizar en su comprensión, sino también, en la nueva perspectiva que brinda a la construcción del problema a investigar. La religión, desde una perspectiva sociológica, constituye un conjunto de creencias que operan como bancos de sentido para la formación de una espiritualidad basada en la metáfora de la divinidad representada en la existencia de Dios, Esta metaforización de lo divino, incide en la formación moral y política de los sujetos y en la construcción de sus relaciones con los otros y con las instituciones, tanto en el espacio público como en el privado. Es así como la religión hace del ser humano un sujeto que en sus prácticas y experiencias, participa activamente del mundo, de una manera particular.

Actualmente en Iberoamérica, se observa una apertura al pluralismo religioso, amparado en el derecho a la libertad de cultos. En consecuencia, los sujetos deciden libremente sobre su pertenencia a un culto religioso determinado que inspire sus vidas. En este contexto, se observa la fuerza y presencia de al menos dos grandes 
religiones: la iglesia católica apostólica Romana y la iglesia Evangélica protestante. Estos cultos religiosos inspiran formas y estilos de vida, de trabajo, de promoción de valores y actitudes diferenciados que inciden en la construcción de ciudadanía, sobre la base de visiones diferentes sobre el bienestar general.

Siguiendo este último hilo de reflexión, avancemos en el abordaje de la tercera categoría.

\section{Sobre la categoría de ciudadanía}

En la revisión del presente estado del arte, se abre un eje analítico sobre la categoría "ciudadanía", entendiendo que se trata también de una categoría multidimensional y polisémica, cuyas diferentes relaciones conceptuales y diferentes concepciones disciplinares hacen complejo su abordaje. En el rastreo realizado, se encuentra que la sociología aborda la cuestión de la ciudadanía desde preguntas por su origen histórico, evolución, desarrollo y su relación con los derechos y con el Estado. Desde la filosofía política, se discute el carácter, la definición de ser ciudadano, sus sentidos y la relación con la democracia como los derechos políticos y civiles.

Tomando como marco conceptual la propuesta de Castoriadis (2007) de entender la ciudadanía como institución de la sociedad, la cual es atravesada por una red de significaciones que sostienen y dirigen la vida de una sociedad; es decir, le otorga sentido y sostén al magma de significaciones imaginarias sociales, podemos encontrar en el relevamiento bibliográfico, algunos hilos conductores sobre estos elementos, expresados en los objetivos y preguntas comunes, donde se evidencia una multiplicidad de relaciones en torno a este objeto de estudio, las cuales pueden ser agrupadas en las siguientes tendencias:

a. Ciudadanía y religiosidad: En esta tendencia, los trabajos revisados muestran como hallazgo relevante, la relación existente entre los diversos elementos que constituyen la ciudadanía y los aspectos que desde la religiosidad resultan afines a su configuración y desarrollo. Uno de estos aspectos hace referencia a la noción de solidaridad que está contenida prescriptivamente en las distintas visiones religiosas y a su vez, hace parte constitutiva de la ciudadanía, como un factor de cohesión social y convivencia pacífica.

b. Epistemología y ontología de la ciudadanía: La ciudadanía es un estatuto de toda persona que vive en una sociedad libre, en la cual se garantice un orden político democrático que permita el ejercicio de las libertades; También es considerada una condición voluntaria que no puede imponerse a ninguna persona, aunque en un Estado de Derecho dicha condición es obligatoria dentro del orden legal y se desglosa en un conjunto de derechos y deberes de las personas que pertenecen a dicho Estado. Como lo sostiene 
Carracedo (2017) en relación con Rousseau, la calidad de ciudadano se funda en el pacto social, en un acuerdo libre de las personas para integrarse y participar en un determinado modelo de organización política.

c. Ciudadanía, democracia y lo público: Según Mejías (2012) la ciudadanía puede ser vista, por una parte, como condición de poder, a través del cual un conjunto de individuos lucha por reconocimiento de derechos en un espacio de conflicto en el que se busca superar las desigualdades; por otra parte, puede ser considerada como el espacio especial de libertad de las prácticas de derecho y deberes democráticos que trascienden los límites de una institucionalidad estatal y nacional. En suma, la ciudadanía se presenta como ejercicio de la política y expresión de lo político, entendido lo político como procedimiento, como reglas, normas, formas a través de las cuales se ejerce la política. En otro sentido, la ciudadanía está relacionada con la construcción social de la democracia y por ello, la ciudadanía en el escenario de la globalización avanza hacia una gobernanza global, donde se requiere con urgencia, una deconstrucción de lo que hasta ahora hemos entendido como sujeto ciudadano y sus formas políticas de participación, para avanzar hacia la integración y la colaboración global. Una ciudadanía vinculante al ejercicio activo de la vida pública de los individuos, organizaciones o instituciones que componen un Estado (Sandia (2012), Kriger y Daiban (2015), Silva-Nova, et. al (2015) Rivas, E (2017).

d. Historia y ciudadanía: El trasfondo de la categoría ciudadanía en términos generales ha dado referencia a un estatus de pertenencia a un grupo social en el cual, se comparten aspectos como la cultura, la identidad y la partencia a un territorio especifico, es decir, la nacionalidad. Pero el concepto ha sido resignificado en el desarrollo en la historia hasta los tiempos actuales (Orozco y Domínguez, 2017). Una característica sobresaliente de la resignificación histórica de la categoría "ciudadanía", tiene que ver con su estrecha relación con la democracia actual como régimen y como procedimiento y la lucha que conlleva para que el sujeto sea artífice y participante activo en los asuntos políticos, con énfasis en la representación directa en los asuntos de lo público (Ramos, 2015, Habermas, 1998 y Kymlicka \& Norman, 1997). Los múltiples abordajes que resignifican la categoría de ciudadanía en la historia traen todo un banquete de clases y definiciones que obligan a quien desee tratar este tema, a situarse, tomar posición respecto a una de ellas, con el fin de evitar el riesgo de entrar en tensión o contradicción con definiciones incompatibles. Tal es el caso de la ciudadanía activa, la ciudadanía ambiental, la ciudadanía cosmopolita, la ciudadanía crítica, la ciudadanía diferenciada, la ciudadanía expandida, la ciudadanía económica, la ciudadanía global, la ciudadanía intercultural, la 
ciudadanía local, multicultural, múltiple, paritaria, digital, entre otras (Ramos, 2016).

e. La ciudadanía ideal: Las diferentes investigaciones analizadas tienen en común un enfoque prescriptivo desde el cual plantean una noción de ciudadanía ideal o ciudadanía utópica, proponiendo modelos de ciudadanía, dentro de los cuales se exploran los posicionamientos subjetivos de jóvenes ciudadanos. Los estudios hechos por Rebolledo (2010), Echeverri (2012), Sandia (2012), Escobar (2013) Muñoz( 2013), Adonaí (2015), Kriger y Daiban (2015) y Rivas (2017), abarcan este asunto desde diversas relaciones con otras categorías relacionadas tales como resistencia, deber, protestantismo, lo público, la democracia, la discriminación, la explotación, la desigualdad, el catolicismo, la ciudadanía religiosa, la ciudadanía activa, la ciudadanía fragmentada, entre otros; todos estos elementos configuran un campo analítico que da sustento a esta ciudadanía utópica.

El trabajo de simplificar el análisis de la categoría "ciudadanía", nos deja con los siguientes aportes. En primer lugar, se identifica una noción de ciudadanía comprendida como institución de sociedad, la cual es atravesada por la red de significaciones que sostienen y dirigen la vida social. En segundo lugar, se propone una relación estrecha entre ciudadanía y religiosidad, señalando la delimitación de un objeto de estudio específico. En tercer lugar, se aborda la ciudadanía como una condición voluntaria y de derechos, vinculada a un pacto social. En cuarto lugar, la ciudadanía es vista como instituyente de la política y expresión de lo político instituido.

\section{Reflexiones finales}

El objeto de este estado del arte fue identificar las tendencias teóricas, metodológicas y los resultados más relevantes, en los estudios relacionados con los imaginarios de ciudadanía política, en jóvenes protestantes evangélicos en iberoamericana. A partir de estas pretensiones y del acervo investigativo recogido, se estructuró el análisis del cual se derivan las siguientes reflexiones:

En relación con el nivel descriptivo se observó que a nivel de doctorado no se encontraron trabajos en investigación en torno a imaginarios sobre ciudadanía política en jóvenes protestantes, lo que significa que es un campo con muchas posibilidades de investigación. En cuanto a la metodología, el hecho de que el 98\% responde a investigaciones de tipo cualitativo, señala la necesidad de complementar dichas investigaciones con la inclusión de algunas herramientas del método cuantitativo. Igualmente, se señala que, en estos estudios cualitativos, se privilegian técnicas de análisis cualitativo tales como el análisis de discurso, pues más del $40 \%$ de los estudios revisados, utilizan como unidades de análisis, los 
textos producidos por los sujetos informantes, dejando un poco marginalmente otras técnicas como las derivadas de la semiótica y la observación.

En cuanto a los métodos empleados, se observa un fuerte énfasis en el enfoque hermenéutico, de corte fenomenológico, lo que lleva concluir que la mayoría de las investigaciones buscaron un acercamiento comprensivo hacia el significado esencial de los fenómenos, así como se interrogaron por el sentido y la importancia que éste tiene en relación con los objetos estudiados.

En cuanto al nivel de análisis, se resalta la vinculación que se hace entre las categorías de ciudadanía, religión y juventud, todas ellas como entramados de significación imaginaria; hasta se puede afirmar según el estudio el arte realizado, que todas son imaginarios que se develan y tiene su fuente, como lo sostiene Castoriadis, en un magna de significados. De la misma manera, fue muy potente constatar la prevalencia a asumir gnoseológicamente, la categoría de religiosidad como una significación imaginaria.

Comprender la religiosidad y la ciudadanía, desde la categoría analítica de las significaciones imaginarias permite en primer lugar, ubicar al investigador en un contexto filosófico, al tiempo que un contexto sociológico y psicológico desde donde recoge los aportes de las perspectivas de la complejidad y el construccionismo social. Las significaciones imaginarias son constructos conceptuales desde donde se explica la participación del sujeto en la construcción de la realidad social; son igualmente, explicativas de la potencia creativa de la imaginación colectiva y anónima que mantiene cohesionada y unida a la sociedad. Los imaginarios develan los múltiples sentidos que construyen los sujetos, por tanto, pueden ser usados como herramienta para estudiarlos.

Así mismo, los abordajes teóricos en torno a la categoría Juventud, se caracterizan por asumirla como período transitorio en la vida, capacidad reformativa, construcción histórica y social. Esta categoría es identificada como producción social, determinada por el orden instituido, pero a su vez, con potencialidad para la emancipación porque se configura en las significaciones imaginarias que se mueven entre lo instituido y lo instituyente. En cuanto a la categoría de religión, esta es abordada como práctica y experiencia colectiva, con poder para trasformar ontológicamente a los sujetos y como magma de sentidos que responde a las tendencias predominantes de una cultura globalizada. Por último, los trabajos sobre la categoría de la ciudadanía nos muestran un espectro mucho más complejo, donde las preocupaciones de los investigadores circulan en primer lugar, en torno a la necesidad de legitimar un concepto determinado de ciudadanía, para en segundo lugar, derivar una intencionalidad investigativa especifica frente a su abordaje y desde allí, aportar nuevas formas de tematizarla y comprenderla, a fin de dar respuesta a la complejidad epistémica y teórica que la caracteriza, logrando 
adaptarla a los contextos específicos socio-políticos que actualmente la están determinando.

Bibliografía

Aguilar, B, C. (2014). Significaciones imaginarias sobre ciudad, en niños y niñas de Pereira. Repositorio Universidad de Manizales. Colombia Disponible en URI: http://ridum.umanizales.edu.co:8080/xmlui/handle/6789/1650. 2014-08-26.

Aliaga, F, P. (2012.) Introducción: La investigación en torno a los imaginarios sociales. Un horizonte abierto a las posibilidades. RIPS. Revista de Investigaciones Políticas y Sociológicas [en línea] 2012, 11 (Sin mes) : [Fecha de consulta: 15 de diciembre de 2018] Disponible en: $<$ http://www.redalyc.org/articulo.oa?id=38024616002> ISSN 1577 $239 \mathrm{X}$.

Andrades, R, E. (2017) La transformación de la ciudadanía romana en el fin del Imperio. 2017. Revista de estudios histórico-jurídicos, (39), 61-83.

Aznar, S, F, J. (2018), págs. 45-72El renacer religioso en el siglo XXI. Fideos et Ratio: revista anual de Teología, Doctrina Social de la Iglesia, Ética y Deontología. 2018 . No. 3 ISSN 2444-961X, Religious rebirth in the 21st century. España

Baeza, R., Manuel A. (2018). Imaginarios sociales religiosos: intramundanidad y extramundanidad en la cultura religiosa popular urbana en chile. Revista de Ciencias Sociales, [S.1.], v. 8, n. 9, p. 17, feb. 2018. Chile.ISSN 07172257.

Disponible

en:

$<$ http://www.revistacienciasociales.cl/ojs/index.php/publicacion/article/vi ew/71>.

Beltrán, C, W ,M. (2013). Pluralización religiosa y cambio social en Colombia. En Pluralisation religieuse et changement socinal en Colombio (29). Bogotá, Colombia: theologica xaveriana.

Betancourth, V, O, E. (2017) Elementos de una teoría de ciudadanía en Charles Taylor [recurso electrónico] 2017 URI: http://hdl.handle.net/10893/10445 http://hdl.handle.net/10893/10445

Bianchetti, S, A, F. (2016) ¿Qué tipo de ciudadanos se intenta formar? (2016). Revista mexicana de investigación educativa,21(69), 647-653. 
http://www.scielo.org.mx/scielo.php?script=sci_arttext\&pid=S1405$\underline{66662016000200647 \& \operatorname{lng}=\text { es\&tlng }=\text { es }}$

Bonifacio, J. (2015) Religión e Incidencia Publica. Contacto editorial Religión e Incidencia Pública Grupo de Estudios Multidisciplinarios en Religión e Incidencia Pública (GEMRIP) 2424, depto. 29 Ciudad Autónoma de Buenos Aires, Argentina revista@gemrip.com.ar emilio.pierpoint.com. ISSN $1853-4783$ http://religioneincidenciapublica.gemrip.org/?page_id $=75$

Carballo, F, H. (2016) Tolerancia religiosa en el republicanismo2016-05-27 Vol. 21 Núm. 2 (2016). Anuario de Historia Regional y de las Frontera. Universidad de Antioquia y Universidad Pontificia Bolivariana DOI: https://doi.org/10.18273/revanu.v21n2-2016010.

Carbonelli, M, A. (2011) Ciencias sociales, evangélicos y política: Una lectura sobre la producción científica acerca de la participación política evangélica en la vida democrática argentina (1983-2010). 2011. Argentina.

Castro, V, H, J. (2017) Análisis global de las nuevas relaciones estado/ciudadano en el marco del neoliberalismo político del siglo XXI. 2017-06. Universidad Autónoma de Madrid. Grupo de Estudios de Relaciones Internacionales. Relaciones Internacionales 35 (2017): 13-34 ISSN: 16993950. URI: http://hdl.handle.net/10486/678916 .

Centeno, J. (2017) Identidad y libertad religiosas en Colombia: Implicaciones para la iglesia pentecostal. 2017. Revista digital de la División de Investigación de la Fundación Universitaria Seminario Bíblico de Colombia ISSN 2027 6958 (En línea) / Publicación Semestral Año 9 Edición 13.

Daiban, C, K. (2011) Del ideal del ciudadano al ciudadano en-situación: un estudio sobre los modelos de ciudadanía y los posicionamientos subjetivos de jóvenes ciudadanos en la Argentina actual (Buenos Aires y Conurbano, 2011-13); Universidad Pedagógica Nacional. Facultad de Humanidades; Folios; 41; 3-2015; 87-10. Argentina.

Espinosa, F, J. (2018) La crítica de la teología política en Toland. 15 diciembre 2018. Hispania Sacra, [S.1.], v. 70, n. 141, p. 95-104, june 2018. ISSN 1988-4265.

Disponible

en: $<\mathrm{http}$ ://hispaniasacra.revistas.csic.es/index.php/hispaniasacra/article/view /734>. doi:http://dx.doi.org/10.3989/hs.2018.009. 
Figueroa, S. H, H. (2016) El protestantismo colombiano: sus orígenes, luchas y expansión (1856-1991). 2016. Source: Revista Cultura y Religión. enejun2016, Vol. 10 Issue 1, p66-87. 22p. Author(s): Colombia.

Gaona, P, J, C. (2018). Representaciones del sujeto evangélico colombiano en su discurso regeneracionista durante la primera mitad del siglo XX. Sociedad y religión, 28(49), 135-164. Recuperado en 14 de diciembre de 2018, de http://www.scielo.org.ar/scielo.php?script=sci arttext\&pid=S1853$70812018000100006 \& \operatorname{lng}=$ es\&tlng=es.

Gómez, G, R,Á. (2013) Juventud Teología y construcción de ciudadanía. 2013. Centro de Estudios Avanzados en Niñez y Juventud alianza de la Universidad de Manizales y el CINDE Editorial/Editor 2013 Fecha Colección. "http://biblioteca.clacso.edu.ar/Colombia/alianza-cindeumz/20140805071901/rafaelalgelgomez.pdf" URL Reconocimiento-No Comercial-Sin Derivadas CC BY-NC-ND http://creativecommons.org/licenses/by-nc-nd/2.0/deed.es

Gómez, S., J, M. (2017) Subjetividades Políticas en Resistencia a través de la Fe: el Caso de la Comunidad Menonita Veráguas. 2017. Universidad distrital Francisco José de Caldas. Bogotá d.c http://hdl.handle.net/11349/7207.

Gómez, P A. (2017) Imaginarios sociales y análisis semiótico. una aproximación a la construcción narrativa de la realidad. 2017. Cuadernos de la Facultad de Humanidades y Ciencias Sociales - Universidad Nacional de Jujuy 2001, (febrero):

Disponible en: $<$ http://www.redalyc.org/articulo.oa?id=18501713> ISSN 0327-1471. España.

Hurtado, H, D, R. (2007), \& Alvarado S, S V. 2007. Escuela y Ciudadanía: reflexiones desde las significaciones imaginarias y la autoreflexi vidad. Estudios pedagógicos (Valdivia), 33(1), 79-93. https://dx.doi.org/10.4067/S0718-07052007000100005

Hurtado, H, D, R. (2008) La configuración: un recurso para comprender los entramados de las significaciones imaginarias. 2008. Revista Latinoamericana de Ciencias Sociales, Niñez y Juventud. http://hdl.handle.net/20.500.11907/546ISSN 1692-715X. Colombia.

Leyton, D. (2009) Jóvenes, una aproximación para abordar los problemas de la inclusión y reproducción social juvenil. 2009. Revista Sociológica de Pensamiento Crítico - 1ISSN 1887 - 3898http://www.intersticios.es Universidad Alberto Hurtado. Vol. 3 (1) Chile. 
Mansilla, M, A. (2015) Sepúlveda, Juan, \& Orellana, Luis. 2015. Cuando el opio se rebela: La Confraternidad Cristiana de Iglesias (Evangélicas) en su crítica a la dictadura militar y su proyecto de sociedad (1981-1989). Revista de ciencia política (Santiago), 35(2), 327-345. https://dx.doi.org/10.4067/S0718-090X2015000200004. Chile.

Martín, B, J. (2008) La ciudadanía: Un deber planetario. 2008. Escuela Superior de Administración Pública (ESAP). https://doi.org/10.22395/seec.v17n35a8 Vol. 17 Núm. 35 (2014), Colombia.

Martím, B, J. (2008). Lo público: experiencia urbana y metáfora ciudadana. CIC. Cuadernos de Información y Comunicación, 13, 213-226. $\leq$ http://www.redalyc.org/articulo.oa?id=93511742013 >ISSN 11357991. Medellín, Colombia

Medina M, E y Villota, Y, M, N. (2015). El Joven Político a dos colores: Las Representaciones Sociales a los ojos de los adultos, las y los adolescentes y jóvenes de dos ciudades del país. Centro Internacional de Educación y Desarrollo Humano-CINDE. Bogotá.

Mejías S, C. Henríquez R, P. (2012) La ciudadanía como co-construcción de espacios de participación en lo público. 2012, $14 .<$ http://www.redalyc.org/articulo.oa?id=86824787009 $>$ ISSN 1517-4522. Brasil.

Molina, G, A. (2015). Procesos de formación para una ciudadanía activa. Revista electrónica de investigación educativa, 17(1), 1-4. http://www.scielo.org.mx/scielo.php?script=sci arttext\&pid=S1607-. México.

Molina, C, W, M, \& Álvarez V, C. (2017). Imaginarios sociales sobre lo juvenil en el Chile contemporáneo. Revista Latinoamericana de Ciencias Sociales, Niñez $\quad y \quad$ Juventud, 15(1), 8516. https://dx.doi.org/10.11600/1692715x.1510407032016 . Chile.

Mosqueira, M, A. (2011) "La política requiere de leones, no de ovejas"(1): Participación política en jóvenes cristiano-evangélicos. 2011. I SSN-e: 2318-9282.

Muñoz, M, St. (2017) Aproximación a las subjetividades en el abordaje de las orientaciones sexuales diversas en dos grupos cristianos interdenominacionales (ministerios romanos 6 y kinship) de Bogotá Colombia. 2017 
Mosqueira, M. (2017) "Redimir la política": experiencias de militancia de jóvenes evangélicos de Argentina. 2017. http://hdl.handle.net/11349/5368. universidad distrital francisco José de caldas. Bogotá. Localización: DESIDADES: Revista Electrónica de Divulgación Científica de la Infancia y la Juventud, ISSN-e 2318-9282, Vol. 3, Nº . 8, 2015, págs. 9-18.

Muñoz, C,Á, E. ( 2013) La ciudadanía: un deber planetario. . Colombia Semestre Económico, volumen 17, No. 35, pp. 193-204 • ISSN 0120-6346, enerojunio de 2014, Medellín, Colombia

Nájera E, O (2007). Los nuevos imaginarios religiosos de los jóvenes. Revista de Antropología Experimental no 7, 2007. Texto 11: 143-151. Universidad de Jaén (España). ISSN: 1578-4282 ISSN 1695-9884

Olvera, (2013) Ciudadanía y Democracia Primera edición, mayo de 2008@ 2008, Instituto Federal Electoral Viaducto Tlalpan Núm. 100, esquina Periférico Sur Col. Arenal Tepepan, 14610, México, D. F. ISBN: 970-695-1113Impreso en México/

Pachón S, D. (2018) Filosofía de la liberación y teoría decoloniales. 2018. Colección Nuevas Ideas, No. 5 Bucaramanga, Colombia.

Pineda C, A y Martínez A, L. (2016). Las dudas de Dios. Teología de la liberación, ecología y movimientos sociales. Santander: Otra América. Cuestiones Teológicas, 43(100), 407418. https://dx.doi.org/10.18566/cueteo.v43n100.a09. Medellín

Ramos,G.( 2018) Jóvenes y política: una revisión de estudios desde Latino América. http://dx.doi.org/10.15847/obsOBS12120181162. Ecuador.

Rebolledo, F, E, N. (2016) La construcción de la ciudadanía en el discurso pedagógico del protestantismo liberal: revista La Reforma, 1901-1932 / Eunice Noemí Rebolledo Fica. - 1a ed. - Córdoba: Universidad Nacional de Córdoba. Facultad de Filosofía y Humanidades, 2016. Libro digital, PDF Archivo Digital: descarga y online ISBN 978-950-33-1259-9

Rebolledo, F, E, N. (2014). El protestantismo liberal y las controversias en torno al laicismo a principios del siglo XIX en La Reforma: revista de religión, educación, historia y ciencias sociales dirigida por William Case Morris. Historia de la educación - anuario, 15(1), 118-138. Recuperado en 15 de diciembre de 2018, de http://www.scielo.org.ar/scielo.php?script=sci_arttext\&pid=S2313$92772014000100008 \& \operatorname{lng}=$ es\&tlng=en. 
Rebolledo, F, E, N. (2016)._Trabajo en la formación de la ciudadanía (1900-1930) en" la reforma, revista de religión, educación, historia y ciencias sociales". 2016. Cuadernos de Educación. Vol. 14 Issue 14, p1-18. 18p. Argentina Cuadernos de Educación Año XIV - No 14 - diciembre 2016 ISSN 2344915

Rubio C, J. (2013). Ciudadanía Democrática: un pensamiento vivo de Rousseau. 2013. ISBN-13: 978-8499400686, Biblioteca Nueva (January 1, 2001) España.

Torres C, M. (2018). ¿Por qué Imaginarios sociales? 15.12. 2018.Eduser - Revista de Educação, [S.1.], v. 8, n. 2, jan. 2017. ISSN 1645-4774. Disponível en: $<$ https://www.eduser.ipb.pt/index.php/eduser/article/view/70>.

España.2016.Salas Rueda, Erika P.. (2010). Teoría crítica de la ciudadanía democrática. En-claves del pensamiento, 4(8), 195-199. Recuperado en 15 de diciembre de 2018, de http://www.scielo.org.mx/scielo.php?script=sci_arttext\&pid=S1870879X2010000200011\&lng=es\&tlng=es.Segovia, Juan Fernando. Tolerancia y las religiones de bonsái en John Locke. 14/04/2018. Revista de investigación, Anacronismo e Irrupción, Vol. 8, $\mathrm{N}^{\circ} 14$ Fecha de Recepción: 03/03/2018ISSN: 2250-4982. Argentina.

Sepúlveda R., L \& Vicente B, M. (2013) Del monopolio católico a la explosión pentecostal: pluralización religiosa, secularización y cambio social en Colombia. Bogotá: Universidad Nacional de Colombia, Facultad de Ciencias Sociales. 2013. 500 pp. Sociedad y Religión: Sociología, Antropología e Historia de la Religión en el Cono Sur, vol. XXVI, núm. 45, 2016, pp. 189-193 Centro de Estudios e Investigaciones Laborales Buenos Aires, Argentina

Soto, O., C, D.; Vásquez, J, J, \& Cardona, L., Y, B. (2009). Imaginarios de gente joven sobre política: Vereda Alto Bonito-Manizales, Colombia. Revista Latinoamericana de Ciencias Sociales, Niñez y Juventud [en línea] 2009, 7 (Enero-Junio) : [Fecha de consulta: 15 de diciembre de 2018] Disponible en: $<$ http://www.redalyc.org/articulo.oa?id=77307116> ISSN 1692-715X.

Valencia, L, $\underline{H}$.(2015).Dialéctica de la significación y dialéctica del poder en el pensamiento político de Cornelius Castoriadis. 2015. Prometeica, ISSNe $1852-9488, \underline{N^{\circ} .11,2015}$

Valencia L, H. (2015). Dialéctica de la significación y dialéctica del poder en el pensamiento político de Cornelius Castoriadis. 2015. Prometeica, ISSN- 
e 1852-9488, № 11,2015 (Ejemplar dedicado a: Prometeica - Año V no 11), págs. 93-112,.

Velázquez M, O. (2013). Las representaciones sociales, los imaginarios sociales y urbanos: ventanas conceptuales para el abordaje de lo urbano. 2013. Revista Académica de Investigación Editada por Eumed.net No. 14 Diciembre España ISSN: 19899300 revista.tlatemoani@uaslp.mx. México.

Villaverde, R, M, J. (2018). La profesión de fe de Rousseau. Hispania Sacra, [S.1.], v. 70, n. 141, p. 137-146, june 2018. ISSN 1988-4265. Disponible en: $<$ http://hispaniasacra.revistas.csic.es/index.php/hispaniasacra/article/view /738>. Fecha de acceso: 15 dec. 2018 doi: http://dx.doi.org/10.3989/hs.2018.013. España

Villamil, E. (2014). Ciudadanía protestante y disidencia moral el papel de la prensa religiosa en el debate sobre las libertades religiosas durante 1946 y 1953. Revista CS, ISSN-e 2011-0324, $\mathrm{N}^{\mathrm{o}}$. 13, 2014CS Ciencias Sociales; Santiago de Cali Iss. 13, (Jan-Jun 2014): 112-144. España. 